Alma Mater Studiorum - Università di Bologna DEPARTMENT OF ECONOMICS

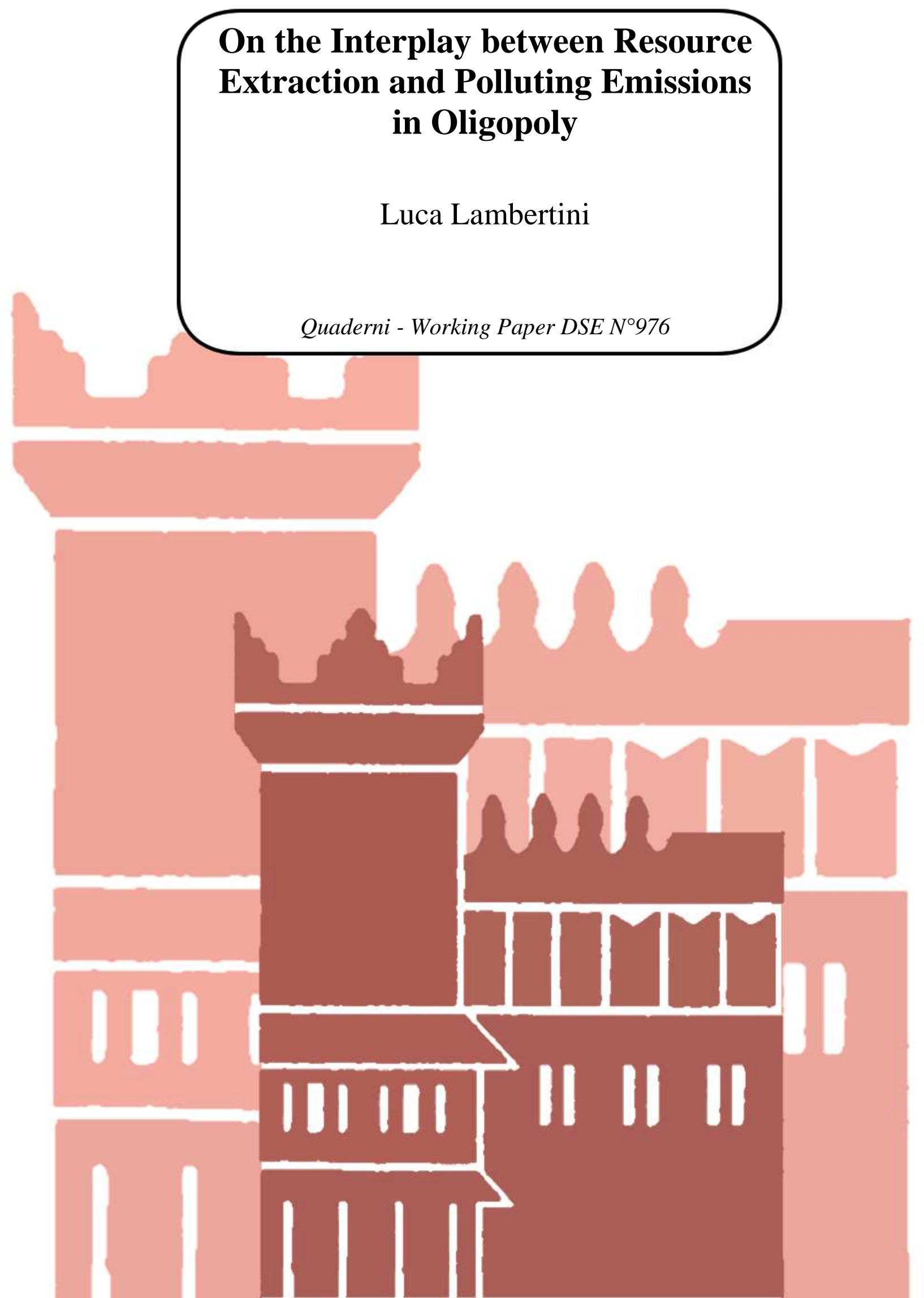




\title{
On the Interplay between Resource Extraction and Polluting Emissions in Oligopoly $^{1}$
}

\author{
Luca Lambertini \\ Department of Economics \\ University of Bologna \\ Strada Maggiore 45, 40125 Bologna, Italy \\ luca.lambertini@unibo.it
}

November 5, 2014

${ }^{1}$ I would like to thank Davide Dragone and Arsen Palestini for useful comments and discussion on an earlier draft. The usual disclaimer applies. 


\begin{abstract}
This paper offers an overview of the literature discussing oligopoly games in which polluti ng emissions are generated by the supply of goods requiring a natural resource as an input. An analytical summary of the main features of the interplay between pollution and resource extraction is then given using a differential game based on the Cournot oligopoly model, in which (i) the bearings on resource preservation of Pigouvian tax rate tailored on emissions are singled out and (ii) the issue of the optimal number of firms in the commons is also addressed.
\end{abstract}

Keywords: pollution, commons, natural resources, green R\&D, emission taxation, differential games

JEL Codes: C73, H23, L13, O31, Q52 


\section{Introduction}

More often than not, the economic theory of natural resources and the environment treats the environmental impact of production/consumption and resource extraction separately. Of course this facilitates the analysis of each of these issues in isolation, but leaves aside the circular nature of the overall problem by overlooking the feedback effects between the two sides of what is in fact a single coin. The interplay I am referring to becomes self evident as soon as one thinks about the fact that, for more than two and a half centuries since the beginning of the industrial revolution, the modern economic systems we are acquainted with have consistently relied on fossil energy sources which are by nature brown and non-renewable to sustain the growth rates of consumption and GDP. This twofold pressure exerted on resources and the environment is compromising the sustainability of economic growth as we know it, as well as the ecosystem's capability to absorb and neutralise greenhouse gases (GHG), leaving no great expectations as for the welfare of generations still to be born, in absence of drastic changes in the nature and impact of productive technologies. The picture is made even gloomier by the possibility of the so-called green paradox looming through the veil of an uncertain future, i.e., the possibility that boosting policy incentives to accelerate the introduction of clean technologies causes a higher extraction rate of fossil fuels, thereby intensifying global warming. ${ }^{1}$

Here, I am setting out to summarise the extant discussion on the interplay between resource extraction and polluting emissions in static and dynamic oligopoly games. Several surveys are already available in this area (see Jørgensen et al., 2010; Long, 2010; and Lambertini, 2013, iter alia). Hence, after outlining the essential features of the problem at hand in this

\footnotetext{
${ }^{1}$ See Sinn (2012) and the related debate (Eichner and Pethig, 2011; Acemoglu et al., 2012; Grafton et al., 2012; Smulders et al., 2012; van der Ploeg and Withagen, 2012; Winter, 2014, inter alia).
} 
introduction, I will offer an overview of the related literature and a dynamic model describing the role of industry structure in a differential game in which profit-maximising firms (i) exploit a common pool resource to supply a consumption good which (ii) pollutes the environment, while (iii) the government adopts an emission tax to stimulate firms' investments in green technologies, and (iv) may regulate the firms' access to the common pool resource (or the industry).

To grasp the essence of the impact of the intensity of competition or industry structure on the environment, it is sufficient to briefly dwell upon the usual interpretation we are used to give to competition versus market power, and then contrast it with the consequences we may expect to emerge from increasing competition in a setup where the environmental consequences of production and/or consumption are duly accounted for. Any increase in competition lowers prices and expands output levels, thereby lowering firms' profits and enhancing consumer surplus. All of this can be summarised under the label of price effect. However, any output expansion associated to the price effect intensifies the pressure on natural resources (accelerating their extraction) and the environment (increasing GHG emissions, for any given set of technologies in use). This is the external effect. Our appraisal of the pros and cons of modifying the number of firms in an industry boils down to the balance between these two effects, and the relative weights we attribute to the components of the welfare function. It is then immediate to infer that the regulation of GHG emissions and resource extraction and its interplay with industry structure and R\&D incentives have simultaneously to do with the tragedy of commons (Gordon, 1954; Hardin, 1968), market integration (or, international trade and globalization), and growth. ${ }^{2}$

\footnotetext{
${ }^{2}$ In the remainder, I will not discuss the literature on the link between resource extraction, environmental externalities and growth as this issue stretches well beyond the scope of the present paper. To this regard, see Schou (2000); Copeland and Taylor (2004); Hart
} 


\section{Related literature}

The core problem that has generated a major stream of research on the interplay between resource extraction, the environmental consequences of production and the possibility of regulating either one or both can be traced back to the idea that those entitled to appropriate the rent generated by natural resources could be affected by carbon taxes allowing governments to reap some of that rent. Unsurprisingly, oligopolistic interaction has not been considered as a fundamental ingredient in modelling this issue. In fact, the backbone of the dynamic analysis carried out on this leitmotiv (Markusen, 1975; Sinclair, 1992, 1994; Ulph and Ulph, 1994; Wirl, 1994; 1995; Hoel and Kverndokk, 1996; Tahvonen, 1996; Rubio and Escriche, 2001) focusses on monopolistic extraction, where this single agent is a cartel (say, OPEC). The resulting discussion can indeed be summarised in a simple model, where accumulated extraction is the only state variable measuring at the same time the stock of pollution at every instant. Hence, one could equivalently think of a situation in which extraction is being taxed. This level of approximation is indeed admissible and even sensible if the decay rate of pollution is very small or, as is currently being stressed by IPCC and several other sources, ${ }^{3}$ the planets' capability of absorbing and neutralising emission is compromised.

The game takes place between an importing country and a monopolistic seller holding the property rights on a brown resource (say, a fossil fuel). The resource stock at time $t$ is $X(t)$ while the extraction rate is determined by the following instantaneous demand function expressed by the importing country:

$$
Q(t)=\max \{0, a-p(t)-\tau(t)\}
$$

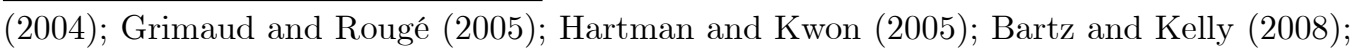
and Itaya (2008).

${ }^{3}$ See IPCC (2007), Le Quéré et al. (2007, 2009) and Stern (2007, 2009). 
where $a$ is a positive constant measuring the choke price, $p(t)$ is the price set by the foreign monopolist, and $\tau(t)$ is the tax rate applied onto the resource by the importing country's government. For all $a>p(t)+\tau(t)$, the tax revenue is $R(t)=\tau(t) Q(t)$ and consumer surplus is $C S(t)=Q^{2}(t) / 2$.

The stock externality is $D(t)=S^{2}(t)$, whose dynamics is

$$
\dot{S}=Q(t)=a-p(t)-\tau(t)
$$

where the decay rate is nil and therefore the environmental damage is irreversible.

The tax revenue is being redistributed to the citizens of the importing country, whose instantaneous welfare function is therefore defined as follows:

$$
S W(t)=C S(t)+R(t)-D(t)
$$

so that the problem of the government is

$$
\max _{\tau(t)} \int_{0}^{\infty} S W(t) e^{-\rho t} d t
$$

under the constraints posed by the state equation (3) and the initial condition $S(0) \geq 0$.

The monopolistic seller's objective consists in solving the following problem:

$$
\max _{p(t)} \int_{0}^{\infty}[p(t)-c S(t)][a-p(t)-\tau(t)] e^{-\rho t} d t
$$

under the same set of constraints. It is worth observing that, in (5), the shape of the extraction cost is determined by the fact that, in equilibrium, the resource consumption is necessarily equal to its extraction rate. Moreover, as a result, cumulative emissions must correspond to cumulative extractions.

Solving this game under imperfect information (i.e., assuming simultaneous moves), Wirl $(1994,1995)$ shows that the outcome of linear feedback strategies Pareto-dominates that generated by non-linear strategies. Tahvonen (1996) extends the analysis to the case of Stackelberg play, with the 
exporting cartel taking the leader's role, and shows that the optimal Pigouvian tax rate is higher that the rate emerging at the Stackelberg equilibrium, proving that the cartel may in fact design its price policy so as to soften the tax pressure and the resulting revenues accruing to the importing country. Rubio and Escriche (2001) revisit the model to shed some new light on the dual role of the emission tax in correcting the externality and extracting a portion of the rent from the supplier's pockets, establishing that the Nash equilibrium tax is neutral in the latter respect, in the sense that it corrects the inefficiency cause by the external effect without affecting the supplier's monopoly power. ${ }^{4}$

A related aspect concerns the intertemporal behaviour of the carbon tax (Sinclair, 1994; Ulph and Ulph, 1994). Shall we expect to observe a monotone relationship between the optimal carbon tax and the residual stock of the natural resource being extracted? According to Sinclair (1992) and Ulph and Ulph (1994), the optimal tax is indeed decreasing over time as the residual resource stock also declines, provided that the percentage reduction in that same stock determines the rate of growth of pollution. However, Ulph and Ulph (1994) show that if instead one allows for a full-fledged picture in which $\mathrm{CO}_{2}$ emissions are not measured by the extraction rate, then the optimal carbon tax is initially increasing (when the stock of pollution is comparatively small) and then decreasing (towards the end of the natural resource's life). ${ }^{5}$

To the best of my knowledge, the extension of this model to allow for proper (i.e., noncooperative) oligopolistic interaction has yet to be pursued. What is available is an extension of the dynamic Cournot game with pol-

\footnotetext{
${ }^{4}$ Rubio and Escriche (2001) also show that the Stackelberg equilibrium in Tahvonen (1996) coincides with the Nash one under feedback rules.

${ }^{5} \mathrm{~A}$ large literature is still flourishing in this vein to explore several additional features and extensions of the basic model. See Amundsen and Schöb (1999); Liski and Tahvonen (2004); Wirl (2007); Daubanes and Grimaud (2010); Wei et al. (2012); Wirl (2012); and Prieur et al. (2013).
} 
luting emissions and taxation proposed by Benchekroun and Long (1998) to account for resource extraction (Dragone et al., 2013b) and green R\&D efforts (Lambertini and Leitmann, 2013). The outline of this analysis is the task performed in the remainder of the paper.

As a preliminary step, I would like to draw your attention to the fact that the foregoing synthesis of a still lively debate takes as a pivotal element the environmental effects of a traded resource whose exploitation is being taxed. These features jointly suggest the presence of an extremely relevant link between the environment and international trade, as mentioned above, and an at least partial equivalence between carbon taxation and tariffs or other trade barriers (cf. Esty, 2001). Moreover, the strategic use of environmental regulation (or lack thereof) may strongly affect firms' location decisions and the flows of FDIs, through the creation of pollution heavens (see Copeland and Taylor, 2004; and Fullerton, 2006). Last but not least, free trade implies an increase of the total number of firms acting in the resulting integrated market, modifying (realistically, increasing) the degree of pressure exerted by any given industry on natural resources and the environment, all else equal. This important aspect can be assessed in a model like the following one, although international trade is not explicitly considered. ${ }^{6}$

\section{The model}

Before delving into the details of the specific model on which the dynamic game I am about to illustrate is based, it is appropriate and useful to outline some general features of the problem posed to a policy maker aiming at regulating the behaviour of a population of firms in an industry where production relies on the extraction of a natural resource and either production

\footnotetext{
${ }^{6}$ For more on the environmental implications of trade, see Copeland and Taylor (1995, 2003, 2005, 2009), Brander and Taylor (1997) and Neary (2006), among many others.
} 
or consumption (or both) entail the emission of pollutants. Let the relevant social welfare function at any given time be

$$
\begin{gathered}
S W(\mathbf{q}(n, \tau))=\Pi(\mathbf{q}(n, \tau), \mathbf{k}(n, \tau), T(\mathbf{q}(n, \tau)))+C S(\mathbf{q}(n, \tau)) \\
+X(\mathbf{q}(n, \tau), D(\mathbf{q}(n, \tau), \mathbf{k}(n, \tau)))+T(\mathbf{q}(n, \tau))-D(\mathbf{q}(n, \tau), \mathbf{k}(n, \tau))
\end{gathered}
$$

where $\mathbf{q}(n, \tau)$ is the vector of quantities chosen by firms, and depends on the number of firms in the industry, $n$, as well as on the level of the emission tax rate $\tau$ set by the government to stimulate green $\mathrm{R} \& \mathrm{D}$ activities $\mathbf{k}(n, \tau)$, and ultimately to diminish the environmental damage $D(\mathbf{q}(n, \tau), \mathbf{k}(n, \tau))$, increasing in $\mathbf{q}(n, \tau)$ and decreasing in $\mathbf{q}(n, \tau)$. The remaining components of social welfare are industry profits $\Pi(\mathbf{q}(n, \tau), \mathbf{k}(n, \tau), T(\mathbf{q}(n, \tau)))$, consumer surplus $C S(\mathbf{q}(n, \tau))$, the residual stock of the natural resource $X(\mathbf{q}(n, \tau), D(\mathbf{q}(n, \tau), \mathbf{k}(n, \tau)))$ (which may well be negatively affected by the impact of the environmental damage) and the total revenue $T(\mathbf{q}(n, \tau))$ generated by the emission tax.

In the light of (6), the government has two instruments, namely, the emission tax $\tau$ and market access (i.e., a limit posed on $n$ ) to regulate this industry. The first tool may alternatively be tuned so as to (i) minimise the environmental damage (in combination with green innovation), or (ii) maximise social welfare as a whole, disregarding the size of each of its components. The second tool - regulating market access - is traditionally viewed as a means to attain the optimal number of firms in the commons. ${ }^{7}$ This, in turn, may consist either in maximising the residual stock of the resource or social welfare (in which case the residual stock must be non negative). ${ }^{8}$

\footnotetext{
${ }^{7}$ See Cornes and Sandler (1983), Cornes, Mason and Sandler (1986), Mason, Sandler and Cornes (1988), Mason and Polasky (1994, 1997) and Dragone et al. (2013b), inter alia.

${ }^{8}$ If resource exploitation is not an issue (or it is simply disregarded), one can still characterise the optimal number of firms in terms of the balance between the environmental damage and overall welfare, as in Katsoulacos and Xepapadeas (1995) and Fujiwara (2009).
} 
In the remainder, I will illustrate a differential oligopoly game envisaging, alternatively, different regulatory menus along these two dimensions. ${ }^{9}$

Consider a Cournot oligopoly with a population $\mathcal{N}=1,2,3, \ldots n$ of singleproduct homogeneous-good firms interacting over continuous time $t \in[0, \infty)$. At any time $t$, the demand function is $p(t)=a-Q(t)$, with $Q(t)=$ $\sum_{i=1}^{n} q_{i}(t), q_{i}(t)$ being the instantaneous individual output of firm $i$. The demand function is based on the assumption that consumers do not internalise any external effects, i.e., consumers in this market have not developed any environmental awareness. All firms use the same productive technology, described by the cost function $C_{i}(t)=c q_{i}(t)$. The production of the final output involves an amount of polluting emissions $s_{i}(t)$ generated by the output of each firm $i$ and evolving according to the following dynamics:

$$
\dot{s}_{i}(t)=\frac{d s_{i}}{d t}=v q_{i}(t)-k_{i}(t)-\delta s_{i}(t),
$$

where $\delta>0$ is a constant decay rate and coefficient $v \geq 0$ measures the volume of $\mathrm{CO}_{2}$-equivalent emissions per unit of output. Variable $k_{i}(t)$ is the instantaneous R\&D effort of firm $i$. The production of the final good requires the extraction of a natural resource $X(t)$ whose stock evolves over time according to the following equation: ${ }^{10}$

$$
\dot{X}(t)=\frac{d X}{d t}=b \sum_{i=1}^{n} q_{i}(t)-z \sum_{i=1}^{n} s_{i}(t)+\eta X(t)
$$

where $b>0$ is the technical coefficient measuring the extraction rate per unit of output, $\eta>0$ is the natural rate of reproduction of the resource itself, and

\footnotetext{
${ }^{9} \mathrm{~A}$ similar but not entirely equivalent approach is adopted in Lambertini and Leitmann (2013), where a dynamic oligopoly model is gradually enriched by inserting additional elements such as emission taxation and green R\&D one by one.

${ }^{10} \mathrm{I}$ am not adopting specific assumptions concerning the positivity of the resource stock (or, conversely, its possible depletion) on doomsday. For more on this, see Lambertini and Mantovani (2014).
} 
parameter $z$ measures the negative impact of polluting emission on the same resource.

The instantaneous cost associated with the $\mathrm{R} \& \mathrm{D}$ activity is $\Gamma_{i}(t)=$ $w k_{i}^{2}(t)$, with $w>0$, and firm $i$ 's emissions $s_{i}(t)$ are taxed at the rate $\tau>0$ at every instant. ${ }^{11}$ Hence, firm $i$ 's instantaneous profits are $\pi_{i}(t)=$ $[p(t)-c] q_{i}(t)-\tau s_{i}(t)-\Gamma_{i}(t)$, and each firm $i$ has to set $q_{i}(t)$ and $k_{i}(t)$ so as to maximise

$$
\Pi_{i}=\int_{0}^{\infty}\left\{[p(t)-c] q_{i}(t)-\tau s_{i}(t)-\Gamma_{i}(t)\right\} e^{-\rho t} d t
$$

under the set of state equations (7) and (8) and the initial conditions $s_{i}(0)=$ $s_{i 0}>0$. Parameter $\rho>0$ represents a constant discount rate common to all firms and the policy maker.

The instantaneous social welfare function is

$$
S W(t)=\sum_{i=1}^{n} \pi_{i}(t)+C S(t)+\tau \sum_{i=1}^{n} s_{i}(t)+X(t)-S^{2}(t)
$$

where $C S(t)=Q^{2}(t) / 2$ is consumer surplus and aggregate emissions $S(t)=$ $\sum_{i=1}^{n} s_{i}(t)$ cause the quadratic environmental damage $S^{2}(t)$.

\section{Equilibrium analysis}

Henceforth, I will omit the time argument for simplicity, whenever possible. Since the present game is a linear state one, the open-loop solution is sub-

\footnotetext{
${ }^{11} \mathrm{~A}$ tax bill defined as a linear function of polluting emissions is commonly used in static models (see Chiou and Hu, 2001; and Poyago-Theotoky, 2007, inter alia). An alternative way of modelling emission taxation consists in assuming that the tax rate is applied to the industry-wide environmentl damage (see Karp and Livernois, 1994; Benchekroun and Long, 1998; 2002; and Dragone et al., 2014, among many others). This is, however, highly unrealistic for several reasons. The choice I make in the present model is in line with the idea that, currently, accurate and verifiable data are indeed available at the individual firm's level (e.g., this is the case in the car industry, where the amount of carbon emissions per kilometer are declared by manufacturers on the websites).
} 
game perfect (or strongly time consistent) as it yields a degenerate feedback equilibrium. ${ }^{12}$ The current-value Hamiltonian of firm $i$ is:

$$
\begin{aligned}
\mathcal{H}_{i}= & (p-c) q_{i}-\tau s_{i}-\Gamma_{i}+\lambda_{i i} \dot{s}_{i}+\sum_{j \neq i} \lambda_{i j} \dot{s}_{j}+\mu_{i} \dot{X}= \\
& =(\sigma-Q) q_{i}-r k_{i}^{2}+\lambda_{i i} \dot{s}_{i}+\sum_{j \neq i} \lambda_{i j} \dot{s}_{j}+\mu_{i} \dot{X}
\end{aligned}
$$

where $\sigma \equiv a-c>0$ denotes the market dimension.

The necessary conditions (FOCs) are:

$$
\frac{\partial \mathcal{H}_{i}}{\partial q_{i}}=\sigma-2 q_{i}-Q_{-i}+v \lambda_{i i}-b \mu_{i}=0,
$$

where $Q_{-i} \equiv \sum_{j \neq i} q_{j}$, and

$$
\frac{\partial \mathcal{H}_{i}}{\partial k_{i}}=-2 w k_{i}-\lambda_{i i}=0,
$$

The adjoint equations read as follows:

$$
\begin{gathered}
\dot{\lambda}_{i i}=(\rho+\delta) \lambda_{i i}+\tau+z \mu_{i} \\
\dot{\mu}_{i}=(\rho-\eta) \mu_{i}
\end{gathered}
$$

and

$$
\dot{\lambda}_{i j}=(\rho+\delta) \lambda_{i j}+z \mu_{i}
$$

From (15-16) we see that the solution $\lambda_{i j}=\mu_{i}=0$ is admissible at all times. This means that, at any instant $t$, firm $i$ fully disregard the dynamics of any rival's emissions as well as the impact of extraction on the stock of the natural resource.

\footnotetext{
${ }^{12}$ For more on the arising of strongly time consistent equilibria in differential games solved under open-loop information, see Fershtman (1987), Mehlmann (1988, ch. 4), Dockner et al. (2000, ch. 7) and Cellini et al. (2005).
} 
Using $\lambda_{i j}=\mu_{i}=0$ and imposing symmetry on states and controls, I may now proceed to use (13) to derive the control equation for the green R\&D effort $k$, as follows:

$$
\dot{k}=-\frac{\dot{\lambda}}{2 w}=-\frac{(\rho+\delta) \lambda+\tau}{2 w}
$$

which, noting - again from (13) - that $\lambda=-2 w k$, can be rewritten as

$$
\dot{k}=\frac{2 w(\rho+\delta) k-\tau}{2 w}
$$

The optimal output associated with the Cournot-Nash equilibrium $(C N)$ at any time $t$ can instead be directly obtained by solving FOC (12):

$$
q^{C N}=\frac{\sigma-2 v w k}{n+1}
$$

which obviously collapses onto the static Cournot-Nash output any green R\&D effort being absent.

I am now in a position to rewrite the state equations as follows:

$$
\begin{gathered}
\dot{s}=\frac{v(\sigma-2 v w k)}{n+1}-k-\delta s \\
\dot{X}=\frac{b(\sigma-2 v w k) n}{n+1}-z n s+\eta X(t)
\end{gathered}
$$

and then impose stationarity on the two states and the R\&D control to obtain the following single triple of steady state values:

$$
\begin{gathered}
k^{*}=\frac{\tau}{2 w(\rho+\delta)} ; s^{*}=\frac{2 \sigma(\delta+\rho) v w-\tau\left(2 v^{2} w+n+1\right)}{2 \delta(n+1)(\delta+\rho) w} \\
X^{*}=\frac{n\left[2 b \delta(\sigma(\delta+\rho)+v \tau) w+\left(2 \sigma(\delta+\rho) v w-\tau\left(2 v^{2} w+n+1\right)\right) z\right]}{2 \delta \eta(n+1)(\delta+\rho) w}
\end{gathered}
$$

Before proceeding, it is worth noting that the expression of $k^{*}$ in (21) reveals that green $\mathrm{R} \& \mathrm{D}$ efforts are observed at equilibrium if and only if $\tau>0$, which is a recurrent theme in static and dynamic models of environmental 
$\mathrm{R} \& \mathrm{D},{ }^{13}$ and, more interestingly, that aggregate equilibrium $\mathrm{R} \& \mathrm{D}$ expenditure is increasing monotonically in the number of firms. In the light of the long-standing querelle about the so called Schumpeterian hypothesis (Schumpeter, 1942) on the direct relationship between innovation incentives and industry concentration, and the opposite position taken by Arrow (1962), one may formulate the following claim:

Lemma 1 For any emission tax rate $\tau$, the pattern of aggregate RED effort at equilibrium is Arrovian.

The above Lemma conveys good news, insofar as increasing industry fragmentation induces the whole sector to intensify its aggregate investment in environmental-friendly technologies, a fact which, in itself, at least partially offsets the negative impact of the price effect.

Using $k^{*}$, the steady state output level rewrites as follows:

$$
q^{*}=\frac{\sigma(\delta+\rho)-v \tau}{(n+1)(\delta+\rho)}
$$

There remains to observe that

$$
\begin{gathered}
s^{*}>0 \forall \tau<\tau_{s}=\frac{2 \sigma(\delta+\rho) v w}{2 v^{2} w+n+1} \\
q^{*}>0 \forall \tau<\tau_{q}=\frac{\sigma(\delta+\rho)}{v}
\end{gathered}
$$

with $\tau_{s}<\tau_{q}$ in the whole admissible range of parameters. Hence, the foregoing analysis proves:

Proposition 2 There exists a unique steady state point $\left\{s^{*}, X^{*}, k^{*}, q^{*}\right\}$, with $s^{*}, X^{*}, k^{*}, q^{*}>0$ for all

$$
\tau<\frac{2 \sigma(\delta+\rho) v w}{2 v^{2} w+n+1}
$$

\footnotetext{
${ }^{13}$ See Chiou and $\mathrm{Hu}$ (2001), Montero (2002), Requate and Unold (2003), PoyagoTheotoky (2007), inter alia. A model in which green R\&D is shown to arise also in absence of any emission tax is in Dragone et al. (2013a). For a survey of the related debate, see Lambertini (2013).
} 
As to the stability properties of the dynamic systems, the following can be shown to hold:

Proposition $3 \eta>\rho$ is a sufficient condition for the steady state $\left\{s^{*}, X^{*}, k^{*}, q^{*}\right\}$ to be a saddle point equilibrium.

Proof. See the Appendix.

In plain words, this amounts to saying that if the natural rate of reproduction of the natural resource exceeds the discount rate applied by firms to future profits (and by the policy maker to the welfare of future generations) then the strategic game generates a stable equilibrium.

At this point, one may note that a policy maker may regulate this industry using two instrument, $\tau$ and $n$, for two different purposes. What if, e.g., the emission tax is fine tuned to eliminate emissions altogether, and entry is limited in such a way that the resulting residual stock of the natural resource is maximised? The first problem is obviously solved setting $\tau=\tau_{s}:{ }^{14}$

\section{Corollary 4 If}

$$
\tau=\tau_{s}=\frac{2 \sigma(\delta+\rho) v w}{2 v^{2} w+n+1}
$$

then the steady state level of emissions is nil.

It is worth stressing that this happens thanks to the firms' $R \& D$ efforts directed at reducing emissions without compromising the positivity of individual Cournot-Nash output levels. If the tax rate $\tau=\tau_{s}$ is indeed adopted, the aggregate green $\mathrm{R} \& \mathrm{D}$ effort at equilibrium is

$$
\left.K^{*}\right|_{\tau=\tau_{s}}=\frac{\sigma n v}{\left(2 v^{2} w+n+1\right)}
$$

\footnotetext{
${ }^{14}$ It is worth stressing that the result stated in Corollary 4 must be taken cum grano salis, as it literally implies a violation of the second law of thermodynamics. What really matters is that the model allows for a degree of environmental innovation sufficient to ensure that the impact of the technology in use be lower than the natural rate of GHG absorption.
} 
with

$$
\frac{\left.\partial K^{*}\right|_{\tau=\tau_{s}}}{\partial n}=\frac{2 \sigma\left(2 v^{2} w+1\right) v}{\left(2 v^{2} w+n+1\right)^{2}}>0,
$$

confirming the result illustrated in Lemma 1.

The other aspect of the regulator's problem refers indeed to identifying the optimal number of firms in the commons. One could think of an access fee to the commons (say, $F$ per firm), which can be left unmodeled if the revenue generated by this source is redistributed to consumers (as it is assumed to be the case for the tax revenue). Relying on the above Corollary, it is easily established that

$$
\left.\frac{\partial X^{*}}{\partial n}\right|_{\tau=\tau_{s}}=\frac{\sigma(b \delta-n v z)}{\delta \eta(n+1)\left(2 v^{2} w+n+1\right)}=0
$$

in correspondence of

$$
n_{X}=\max \left\{1, \frac{b \delta}{v z}\right\}
$$

with

$$
\left.\frac{\partial^{2} X^{*}}{\partial n^{2}}\right|_{\tau=\tau_{s}}=-\frac{2 \sigma(b \delta+v z)}{\delta \eta(n+1)^{2}\left(2 v^{2} w+n+1\right)}<0 .
$$

This exercise establishes the following result:

Corollary 5 If $z<b \delta / v$, then the industry structure that maximises the residual resource stock in steady state is $n_{X}=b \delta /(v z)>1$. Otherwise, the residual stock is maximised under monopoly.

The consequences of choosing the pair $\left(n_{X}, \tau_{s}\right)$ on welfare are captured by

$$
\begin{gathered}
\operatorname{sign}\left\{\left.\frac{\partial S W^{*}}{\partial n}\right|_{n=n_{X}, \tau=\tau_{s}}\right\}=\operatorname{sign}\{z+v w(v z-b \delta)\} \\
\left.\frac{\partial S W^{*}}{\partial \tau}\right|_{n=n_{X}, \tau=\tau_{s}}<0 \text { always. }
\end{gathered}
$$

The above expressions imply that choosing $n$ to maximise $X^{*}$ excludes the attainment of welfare maximisation, except in the very special (and extremely 
unlikely) case in which $z+v w(v z-b \delta)=0$. As an alternative, the regulator may set $n$ so as to maximise welfare, in combination with the choice of $\tau_{s}$. If so, we have:

$$
\operatorname{sign}\left\{\left.\frac{\partial S W^{*}}{\partial n}\right|_{\tau=\tau_{s}}\right\}=\operatorname{sign}\left\{-v z n^{2}+\Phi n+\Psi\right\}
$$

where

$$
\Phi \equiv b \delta-v\left[\sigma \delta \eta v w+z\left(1+2 v^{2} w\right)\right]
$$

and

$$
\Psi \equiv \delta\left[\sigma \eta\left(1+v^{2} w\right)+b\left(1+2 v^{2} w\right)\right] .
$$

It is easily ascertained that

$$
\left.\frac{\partial S W^{*}}{\partial n}\right|_{n=0, \tau=\tau_{s}}>0
$$

since $\Psi>0$, and

$$
\operatorname{sign}\left\{\left.\frac{\partial S W^{*}}{\partial n}\right|_{n=1, \tau=\tau_{s}}\right\}=\operatorname{sign}\left\{\delta\left[\sigma \eta+2 b\left(1+v^{2} w\right)\right]-2 v z\left(1+v^{2} w\right)\right\}
$$

which is positive - for instance - if market size $\sigma$ is sufficiently large or $z$ (measuring the negative impact of emissions on the natural resource) is low enough. If indeed the sign of (36) is positive, then

$$
\left.\frac{\partial S W^{*}}{\partial n}\right|_{\tau=\tau_{s}}=0 \text { in } n_{S W}=\frac{-\Phi+\sqrt{\Phi^{2}+4 v z \Psi}}{2 v z}
$$

with $n_{S W}>b \delta /(v z)$ iff $z+v w(v z-b \delta)>0$. Taking into account (30), this yields:

Proposition 6 Suppose $z+v w(v z-b \delta)>0$. If so, then at $n=n_{S W}$ it is necessarily true that $\partial X^{*} /\left.\partial n\right|_{\tau=\tau_{s}}<0$. 
The above result raises one last question, namely, whether the industry structure that maximises social welfare entails resource exhaustion or not. The answer is swiftly delivered by substituting $\tau_{s}$ into $X^{*}$, which can be simplified as follows:

$$
\left.X^{*}\right|_{\tau=\tau_{s}}=\frac{b n \sigma}{\eta\left(2 v^{2} w+n+1\right)}>0
$$

for all admissible values of $n$, obviously including $n_{S W}$. This finding produces one last claim:

Corollary 7 The industry structure maximising the equilibrium level of social welfare, coupled with the emission tax rate minimising the environmental impact of production, allows for the preservation of a strictly positive stock of resource in steady state.

In a nutshell, what the above Corollary says is that the industry structure that maximises welfare as a result of a compromise between expanding the usual components of welfare (i.e., producer and consumer surplus) in absence of externalities or when the latter are disregarded is compatible with the minimization of polluting emissions (which is obvious, as $\tau$ is set at $\tau_{s}$ ) and with the preservation of a positive volume of the natural resource stock.

\section{Concluding remarks}

The above model delivers a few positive messages, namely, that there exists a tax policy which may minimise total emissions and simultaneously stimulate green $\mathrm{R} \& \mathrm{D}$ whose volume is increasing in the number of firms. However, allowing access to the commons to additional firms may compromise the preservation of the resource stock, which might benefit from granting monopoly power. This specific feature brings the discussion back to the earlier model on which an entire stream of literature is based, where indeed 
monopoly was assumed as representative of cartels controlling natural resources, in particular fossil fuels.

All of this apparently implies the following. Understanding the interplay between pollution and resource exploitation and design the most efficient policy measures is, most probably, one of the most challenging task posed to the economic theory of natural resources and the environment, as it requires a thorough analysis of many equally important factors such as the intensity of competition, market integration, a menu of policy instruments and technical progress, all of which are put together in a single melting pot.

\section{Appendix: Proof of Proposition 3}

The stability properties of the model can be assessed relying on Dockner's (1985) method (as illustrated in Dockner and Feichtinger, 1991; for more, see also Kemp et al., 1993).

From FOCs (12-13), one obtains the optimal output $q^{C N}$ in (19) and the Nash equilibrium R\&D effort $k^{N}=\lambda /(2 w)$. These values can be substituted into (11) to write the maximised Hamiltonian $\mathcal{H}^{N}(\lambda, \mu, s, X)$, imposing additionally the symmetry conditions $s_{i}=s, \lambda_{i i}=\lambda$ and $\mu_{i}=\mu$ for all $i$, as well as $\lambda_{i j}=0$ for all $j \neq i$. This procedure delivers the following expression:

$$
\begin{aligned}
& \mathcal{H}^{N}(\lambda, \mu, s, X)=\frac{(\sigma+v \lambda-b \mu)[a-n(v \lambda-b \mu)]}{(n+1)^{2}}-\tau s-\frac{\lambda^{2}}{4 w^{2}}+ \\
& \lambda\left[\frac{v(\sigma+v \lambda-b \mu)}{n+1}+\frac{\lambda}{2 w}-\delta s\right]+\mu\left[\frac{n(\sigma+v \lambda-b \mu)}{n+1}\right]-n z s+\eta X
\end{aligned}
$$

Then, one can construct the following $4 \times 4$ Jacobian matrix:

$$
J=\left[\begin{array}{cc}
\mathcal{H}_{\omega \varsigma}^{N} & \mathcal{H}_{\omega \omega}^{N} \\
-\mathcal{H}_{\varsigma \varsigma}^{N} & \rho I-\mathcal{H}_{\varsigma \omega}^{N}
\end{array}\right]
$$

where each $\mathcal{H}_{\alpha \beta}^{*}, \alpha, \beta=\varsigma, \omega$, is a $2 \times 2$ matrix of second-order partial derivatives, $\varsigma \equiv(s, X)$ is the state vector, $\omega \equiv(\lambda, \mu)$ is the costate vector and $I$ is 
the $2 \times 2$ identity matrix. Hence, (a2) rewrites as

$$
J=\left[\begin{array}{cccc}
-\delta & 0 & \frac{(n+1)^{2}+4 v^{2} w}{2(n+1)^{2} v} & -\frac{b\left(n^{2}+1\right) v^{2}}{(n+1)^{2}} \\
-n z & \eta & -\frac{b\left(n^{2}+1\right) v^{2}}{(n+1)^{2}} & \frac{2 b^{2} n^{2}}{(n+1)^{2}} \\
0 & 0 & \delta+\rho & n z \\
0 & 0 & 0 & \rho-\eta
\end{array}\right]
$$

whose determinant is

$$
\Delta_{J}=\delta \eta(\delta+\rho)(\eta-\rho)>0
$$

for all $\eta>\rho$ (and conversely).

Dockner's $\mathcal{K}$ (see Dockner and Feichtinger, 1991, pp. 45-46) is identified by the following expression:

$$
\mathcal{K}=\Delta_{M_{1}}+\Delta_{M_{2}}+2 \Delta_{M_{3}}
$$

where matrices $M_{1}, M_{2}$ and $M_{3}$ are the following:

$$
\begin{gathered}
M_{1}=\left[\begin{array}{cc}
\frac{\partial \dot{s}}{\partial s}=-\delta & \frac{\partial \dot{s}}{\partial \lambda}=\frac{v^{2}}{n+1}+\frac{1}{2 w} \\
\frac{\partial \dot{\lambda}}{\partial s}=0 & \frac{\partial \dot{\lambda}}{\partial \lambda}=\delta+\rho
\end{array}\right] \\
M_{2}=\left[\begin{array}{cc}
\frac{\partial \dot{X}}{\partial X}=\eta & \frac{\partial \dot{X}}{\partial \mu}=\frac{b^{2} n}{n+1} \\
\frac{\partial \dot{\mu}}{\partial X}=0 & \frac{\partial \dot{\mu}}{\partial \mu}=\rho-\eta
\end{array}\right] \\
M_{3}=\left[\begin{array}{cc}
\frac{\partial \dot{s}}{\partial X}=0 & \frac{\partial \dot{s}}{\partial \mu}=-\frac{b v}{n+1} \\
\frac{\partial \dot{\lambda}}{\partial X}=0 & \frac{\partial \dot{\lambda}}{\partial \mu}=z
\end{array}\right]
\end{gathered}
$$


so that $\Delta_{M_{1}}=-\delta(\delta+\rho), \Delta_{M_{2}}=\eta(\rho-\eta)$ and $\Delta_{M_{3}}=0$. Accordingly, expression (a5) simplifies as follows:

$$
\mathcal{K}=\Delta_{M_{1}}+\Delta_{M_{2}}=-\delta(\delta+\rho)+\eta(\rho-\eta)
$$

and $\eta \geq \rho$ is a sufficient condition to ensure $\mathcal{K}<0$. Now, if (i) $\mathcal{K}<0$, (ii) $\Delta_{J}>0$ and (iii) $\mathcal{K}^{2} / 4>\Delta_{J}$ jointly hold, then we have saddle point stability with four real eigenvalues, two being positive and two being negative (cf. Dockner and Feichtinger, 1991, Lemma 2, p. 35). The sufficient condition for this result is indeed $\eta>\rho$. 


\section{References}

[1] Acemoglu, D., P. Aghion, L. Bursztyn and D. Hemous (2012), "The Environment and Directed Technical Change", American Economic Review, 102, 131-66.

[2] Amundsen, E.S. and R. Schöb (1999), "Environmental Taxes on Exhaustible Resources", European Journal of Political Economy, 15, 31129.

[3] Arrow, K. (1962), "Economic Welfare and the Allocation of Resources for Invention", in R. Nelson (ed.), The Rate and Direction of Industrial Activity, Princeton, NJ, Princeton University Press.

[4] Bartz, S. and D.L. Kelly (2008), "Economic Growth and the Environment: Theory and Facts", Resource and Energy Economics, 30, 115-49.

[5] Brander, J.A. and M.S. Taylor (1997), "International Trade and OpenAccess Renewable Resources: The Small Open Economy Case", Canadian Journal of Economics, 30, 526-52.

[6] Benchekroun, H. and N.V. Long (1998), "Efficiency Inducing Taxation for Polluting Oligopolists", Journal of Public Economics, 70, 325-42.

[7] Benchekroun, H. and N.V. Long (2002), "On the Multiplicity of Efficiency-Inducing Tax Rules", Economics Letters, 76, 331-36.

[8] Cellini, R., L. Lambertini and G. Leitmann (2005), "Degenerate Feedback and Time Consistency in Differential Games", in E.P. Hofer and E. Reithmeier (eds), Modeling and Control of Autonomous Decision Support Based Systems. Proceedings of the 13th International Workshop on Dynamics and Control, Aachen, Shaker Verlag, 185-92. 
[9] Chakravorty, U., B. Magne and M. Moreaux (2006), "A Hotelling Model with a Ceiling on the Stock of Pollution", Journal of Economic Dynamics and Control, 30, 2875-2904.

[10] Chakravorty, U., M. Moreaux and M. Tidball (2008), "Ordering the Extraction of Polluting Nonrenewable Resources", American Economic Review, 98, 1128-44.

[11] Chiou, J.-R. and J.-L. Hu (2001), "Environmental Research Joint Ventures under Emission Taxes", Environmental and Resource Economics, 20, 129-46.

[12] Copeland, B.R. and M.S. Taylor (1995), "Trade and the Environment: A Partial Synthesis", American Journal of Agricultural Economics, 77, 765-71.

[13] Copeland, B.R. and M.S. Taylor (2003), Trade and the Environment: Theory and Evidence, Princeton, NJ, Princeton University Press.

[14] Copeland, B.R. and M.S. Taylor (2004), "Trade, Growth, and the Environment", Journal of Economic Literature, 42, 7-71.

[15] Copeland, B.R. and M.S. Taylor (2005), "Free Trade and Global Warming: A Trade Theory View of the Kyoto Protocol", Journal of Environmental Economics and Management, 49, 205-34.

[16] Copeland, B.R. and M.S. Taylor (2009), "Trade, Tragedy, and the Commons", American Economic Review, 99, 725-49.

[17] Cornes, R. and T. Sandler (1983), "On Commons and Tragedies", American Economic Review, 73, 787-92. 
[18] Cornes, R., C.F. Mason and T. Sandler (1986), "The Commons and the Optimal Number of Firms", Quarterly Journal of Economics, 101, $641-46$.

[19] Daubanes, J. and A. Grimaud (2010), "Taxation of a Polluting NonRenewable Resource in the Heterogeneous World", Environmental and Resource Economics, 47, 567-88.

[20] Dockner, E.J. (1985), "Local Stability Analysis in Optimal Control Problems with Two State Variables", in G. Feichtinger (ed.), Optimal Control Theory and Economic Analysis, vol. 2, Amsterdam, NorthHolland, 89-103.

[21] Dockner, E.J. and G. Feichtinger (1991), "On the Optimality of Limit Cycles in Dynamic Economic Systems", Journal of Economics, 53, 3150 .

[22] Dockner, E.J, S. Jørgensen, N. Van Long and G. Sorger (2000), Differential Games in Economics and Management Science, Cambridge, Cambridge University Press.

[23] Dragone, D., L. Lambertini and A. Palestini (2013a), "The Incentive to Invest in Environmental-Friendly Technologies: Dynamics Makes a Difference", in J. Crespo Cuaresma, T. Palokangas and A. Tarasjev (eds), Green Growth and Sustainable Development, Heidelberg, Springer, 16588.

[24] Dragone, D., L. Lambertini and A. Palestini (2014), "Regulating Environmental Externalities through Public Firms: A Differential Game", Strategic Behavior and the Environment, 4, 15-40. 
[25] Dragone, D., L. Lambertini, A. Palestini and A. Tampieri (2013b), "On the Optimal Number of Firms in the Commons: Cournot vs Bertrand", Mathematical Economics Letters, 1, 25-34.

[26] Eichner, T. and R. Pethig (2011), "Carbon Leakage, the Green Paradox, and Perfect Future Markets", International Economic Review, 52, 767805.

[27] Esty, D.C. (2001), "Bridging the Trade-Environment Divide", Journal of Economic Perspectives, 15, 113-30.

[28] Fershtman, C. (1987), "Identification of Classes of Differential Games for Which the Open-Loop is a Degenerated Feedback Nash Equilibrium", Journal of Optimization Theory and Applications, 55, 217-31.

[29] Fujiwara, K. (2009), "Environmental Policies in a Differentiated Oligopoly Revisited", Resource and Energy Economics, 31, 239-47.

[30] Fullerton, D. (2006, ed.), The Economics of Pollution Havens, Cheltenham, Edward Elgar.

[31] Gans, J. (2012), "Innovation and Climate Change Policy", American Economic Journal: Economic Policy, 4, 125-45.

[32] Gordon, H.S. (1954), "The Economic Theory of a Common-Property Resource: The Fishery", Journal of Political Economy, 62, 124-42.

[33] Grafton, Q., T. Kompas and N.V. Long (2012), "Substitution between Biofuels and Fossil Fuels: Is there a Green Paradox?", Journal of Environmental Economics and Management, 64, 328-41.

[34] Grimaud, A. and L. Rougé (2005), "Polluting Non-Renewable Resources, Innovation and Growth: Welfare and Environmental Policy", Resource and Energy Economics, 27, 109-29. 
[35] Hardin, G. (1968), "The Tragedy of the Commons", Science, 162, 124348.

[36] Hart, R. (2004), "Growth, Environment and Innovation - A Model with Production Vintages and Environmentally Oriented Research", Journal of Environmental Economics and Management, 48, 1078-98.

[37] Hartman, R. and O.S. Kwon (2005), "Sustainable Growth and the Environmental Kuznets Curve", Journal of Economic Dynamics and Control, 29, 1701-36.

[38] Hoel, m. and S. Kverndokk (1996), "Depletion of Fossil Fuels and the Impacts of Global Warming", Resource and Energy Economics, 18, 11536 .

[39] Intergovernmental Panel on Climate Change (IPCC) (2007), Climate Change 2007: Synthesis Report, Geneva, IPCC.

[40] Itaya, J. (2008), "Can Environmental Taxation Stimulate Growth? The Role of Indeterminacy in Endogenous Growth Models with Environmental Externalities", Journal of Economic Dynamics and Control, 32, 1156-80.

[41] Jørgensen, S., G. Martín-Herrán and S. Zaccour(2010), "Dynamic Games in the Economics and Management of Pollution", Environmental Modeling and Assessment, 15, 433-67.

[42] Karp, L. and J. Livernois (1994), "Using Automatic Tax Changes to Control Pollution Emissions", Journal of Environmental Economics and Management, 27, 38-48.

[43] Katsoulacos, Y. and A. Xepapadeas (1995), "Environmental Policy under Oligopoly with Endogenous Market Structure", Scandinavian Journal of Economics, 97, 411-20. 
[44] Kemp, M., N.V. Long and K. Shimomura (1993), "Cyclical and Noncyclical Redistributive Taxation", International Economic Review, 34, $415-29$.

[45] Lambertini, L. (2013), Oligopoly, the Environment and Natural Resources, London, Routledge.

[46] Lambertini, L. and G. Leitmann (2013), "Market Power, Resource Extraction and Pollution: Some Paradoxes and a Unified View", in J. Crespo Cuaresma, T. Palokangas and A. Tarasjev (eds), Green Growth and Sustainable Development, Heidelberg, Springer, 143-64.

[47] Lambertini, L. and A. Mantovani (2014), "Feedback Equilibria in a Dynamic Renewable Resource Oligopoly: Pre-Emption, Voracity and Exhaustion", Journal of Economic Dynamics and Control, 47, 115-22.

[48] Le Quéré, C., C. Rodenbeck, E.T. Buitenhuis et al. (2007), "Saturation of the Southern Ocean CO2 Sink Due to Recent Climate Change", Science, 316, 1735-38.

[49] Le Quéré, C., M.R. Raupach, J.G. Canadell et al. (2009), "Trends in the Sources and Sinks of Carbon Dioxide", Nature Geoscience, 2, 831-36.

[50] Liski, M. and O. Tahvonen (2004), "Can Carbon Tax Eat OPEC's Rents?", Journal of Environmental Economics and Management, 47, $1-12$.

[51] Long, N.V. (2010), A Survey of Dynamic Games in Economics, Singapore, World Scientific.

[52] Markusen, J.R. (1975), "Cooperative Control of International Pollution and Common Property Resources", Quarterly Journal of Economics, 89, $618-32$. 
[53] Mason, C. and S. Polasky (1994), "Entry Deterrence in the Commons", International Economic Review, 35, 507-25.

[54] Mason, C.F. and S. Polasky (1997), "The Optimal Number of Firms in the Commons: A Dynamic Approach", Canadian Journal of Economics, 30, 1143-60.

[55] Mason, C., T. Sandler and R. Cornes (1988), "Expectations, the Commons, and Optimal Group Size", Journal of Environmental Economics and Management, 15, 99-110.

[56] Mehlmann, A. (1988), Applied Differential Games, New York, Plenum Press.

[57] Montero, J.-P. (2002), "Market Structure and Environmental Innovation", Journal of Applied Economics, 5, 293-325.

[58] Neary, J.P. (2006), "International Trade and the Environment: Theoretical and Policy Linkages", Environmental and Resource Economics, 33, 95-118.

[59] Poyago-Theotoky, J. (2007), "The Organization of R\&D and Environmental Policy", Journal of Economic Behaviour and Organization, 62, 63-75.

[60] Prieur, F., M. Tidball and C. Withagen (2013), "Optimal EmissionExtraction Policy in a World of Scarcity and Irreversibility", Resource and Energy Economics, 35, 637-58.

[61] Requate, T. and W. Unold (2003), "Environmental Policy Incentives to Adopt Advanced Abatement Technology - Will the True Ranking Please Stand Up?", European Economic Review, 47, 125-46. 
[62] Rubio, S. and L. Escriche (2001), "Strategic Pigouvian Taxation, Stock Externalities and Non-Renewable Resources", Journal of Public Economics, 79, 297-313.

[63] Schou, P. (2000), "Polluting Non-Renewable Resources and Growth", Environmental and Resource Economics, 16, 211-27.

[64] Schumpeter, J.A. (1942), Capitalism, Socialism and Democracy, New York, Harper.

[65] Sinclair, P. (1992), "High Does Nothing and Rising Is Worse: Carbon Taxes Should Keep Declining to Cut Harmful Emissions", Manchester School, 60, 41-52.

[66] Sinclair, P. (1994), "On the Trend of Fossil Fuel Taxation", Oxford Economic Papers, 46, 869-877.

[67] Sinn, H.-W. (2012), The Green Paradox: A Supply-Side Approach to Global Warming, Cambridge, MA, MIT Press.

[68] Smulders, S., Y. Tsur and A. Zemel (2012), "Announcing Climate Policy: Can a Green Paradox Arise without Scarcity?", Journal of Environmental Economics and Management, 64, 364-76.

[69] Stern, N. (2007), The Economics of Climate Change: The Stern Review, Cambridge, Cambridge University Press.

[70] Stern, N. (2009), A Blueprint for a Safer Planet. How to Manage Climate Change and Create a New Era of Progress and Prosperity, New York, Random House.

[71] Tahvonen, O. (1996), "Trade with Polluting Non-Renewable Resources", Journal of Environmental Economics and Management, 30, 1-17. 
[72] Ulph, D. and A. Ulph (1994), "The Optimal Time Path of a Carbon Tax", Oxford Economic Papers, 46, 857-68.

[73] van der Ploeg, F. and C. Withagen (2012), "Is there Really a Green Paradox?", Journal of Environmental Economics and Management, 64, $342-63$.

[74] Wei, J., M. Hennlock, D.J.A. Johansson and T. Sterner (2012), "The Fossil Endgame: Strategic Oil Price Discrimination and Carbon Taxation", Journal of Environmental Economics and Policy, 1, 48-69.

[75] Winter, R.A. (2014), "Innovation and the Dynamics of Global Warming", Journal of Environmental Economics and Management, 68, 12440 .

[76] Wirl, F. (1994), "Pigouvian Taxation of Energy for Flow and Stock Externalities and Strategic, Noncompetitive Energy Pricing", Journal of Environmental Economics and Management, 26, 1-18.

[77] Wirl, F. (1995), "The Exploitation of Fossil Fuels under the Threat of Global Warming and Carbon Taxes: A Dynamic Game Approach", Environmental and Resource Economics, 5, 333-52.

[78] Wirl, F. (2007), "Energy Prices and Carbon Taxes under Uncertainty about Global Warming", Environmental and Resource Economics, 36, $313-40$.

[79] Wirl, F. (2012), "Global Warming: Prices versus Quantities from a Strategic Point of View", Journal of Environmental Economics and Management, 64, 217-29. 


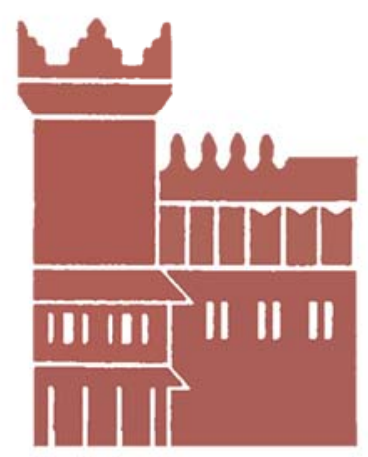

Alma Mater Studiorum - Università di Bologna DEPARTMENT OF ECONOMICS

Strada Maggiore 45

40125 Bologna - Italy

Tel. +39051 2092604

Fax +390512092664

http://www.dse.unibo.it 